\title{
16. FRANKFURT EURO FINANCE WEEK
}

Vom 18. bis 22. November 2013 findet die diesjährige Euro Finance Week in Frankfurt am Main statt.

Mit über 500 Sprechern und 10000 Besuchern aus 60 Ländern ist die Euro Finance Week das größte Branchentreffen der Finanz- und Versicherungsindustrie in Europa. In rund 40 Fachveranstaltungen mit 100 Diskussionsrunden bildet die Veranstaltung an fünf Tagen die aktuellen Themen der Branche ab. Zahlreiche Empfänge und Preisverleihungen ergänzen das inhaltliche Programm und bieten ideale Möglichkeiten zum Networking.

Die Integration und Regulierung der europäischen Finanzund Versicherungsmärkte ist ein jährlicher Themenschwerpunkt der Woche. Ergänzende Fachkonferenzen zu Themen wie unter anderem Retail Banking, Risk Management und Banken-IT vertiefen praxisnah die Fragestellungen, die in den politisch-regulatorisch ausgerichteten Leitkonferenzen aufge- worfen werden. Des Weiteren haben regionale und Länderschwerpunkte einen festen Platz in der Euro Finance Week.

Der „Euro Finance Marketplace“ bietet darüber hinaus weitere Gelegenheit, sich als Unternehmen mit einem Stand prominent während der Euro Finance Week zu präsentieren und mit den Besuchern der Veranstaltungswoche Kontakte zu knüpfen.

Den traditionellen Abschluss findet die Veranstaltungswoche mit dem „Frankfurt European Banking Congress“ in der Alten Oper Frankfurt sowie am Abend desselben Tages mit der glanzvollen „Benefiz Gala“, ebenfalls in der Alten Oper.

Weitere Informationen zu Programm, Teilnahmegebühr und vielem mehr finden Sie unter: www.malekigroup.com

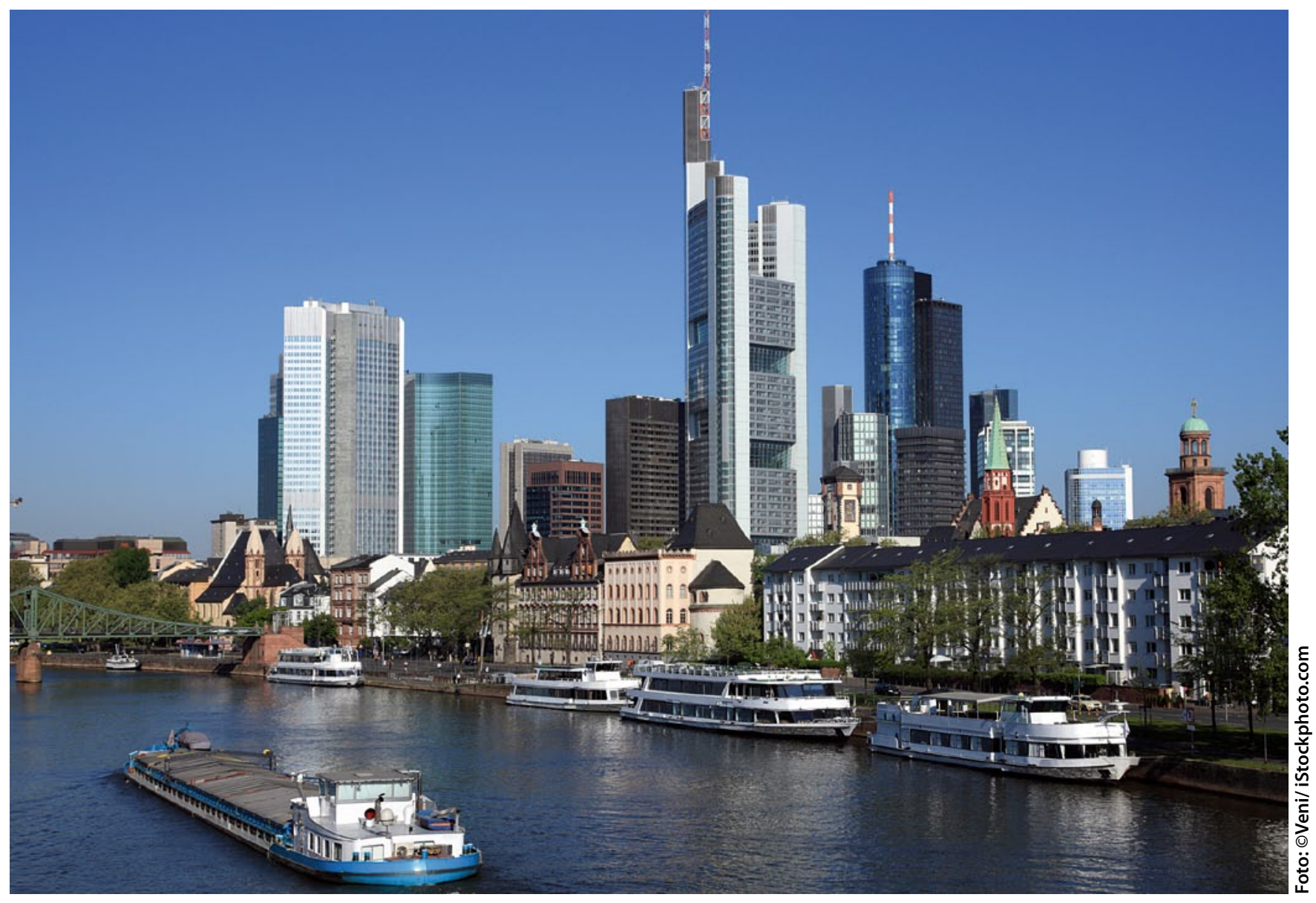

